\title{
Evaluation of stress intensity factor of multiple inclined cracks under biaxial loading
}

\author{
R. K. Bhagat, V. K. Singh, P. C. Gope, A.K. Chaudhary \\ College of Technology, G.B.P.U.A. \& T, Pantnagar-263145, (Uttarakhand), INDLA \\ vks2319@yahoo.co.in
}

\begin{abstract}
A finite rectangular plate of unit thickness with two inclined cracks (parallel and non parallel) under biaxial mixed mode condition are modelled using finite element method. The finite element method is used for determination of stress intensity factors by ANYSIS software. Effects of crack inclination angle on stress intensity factors for two parallel and non parallel cracks are investigated. The significant effects of different crack inclination parameters on stress intensity factors are seen for lower and upper crack in two inclined crack. The present method is validated by comparing the results from available experimental data obtained by photo elastic method in same condition.
\end{abstract}

KEYWORDS. Stress intensity factor; Multiple cracks; Photoelasticity; Crack inclination angle.

\section{INTRODUCTION}

T he fracture mechanics theory can be used to analyze structures and machine components with cracks and to obtain an efficient design. The basic principles of fracture mechanics developed from studies of [1-3] are based on the concepts of linear elasticity. Westergaard [3] derived the general linear elastic solution for the stress field around a crack tip using complex stress functions. Irwin [4], proposed the description of the stress field ahead of a crack tip (front) by means of only one parameter, the so called stress intensity factor (SIF).

The interaction between multiple cracks has a major influence on crack growth behaviours. This influence is particularly significant in stress corrosion cracking (SCC) because of the relatively large number of cracks initiated due to environmental effects. Wen Ye Tian and U Gabbert [5] have proposed pseudo - traction -electric - displacement magnetic -induction method to solve the multiple crack interaction problems in magneto elastic material.

The interaction of multiple cracks in a finite plate by using the hybrid displacement discontinuity method (a boundary element method) and detail solutions of the stress intensity factors (SIFs) of the multiple-crack problems in a rectangular plate are shown by Xiangqiao [6]. The numerical results reported by Xiangqiao [6] illustrates that the boundary element method is simple, yet accurate for calculating the SIFs of multiple crack problems in a finite plate. Flaw interaction effects were investigated and the importance of modelling multiple crack growth at high stress levels was presented by Walde [7]. Wang [8] studied the interactions of two collinear cracks, three collinear cracks, two parallel cracks, and three parallel cracks using finite element technique.

The present investigation have been conducted keeping in mind the effect of crack inclination angle on facture parameters such as stress intensity factor for mode-I problem $\left(\mathrm{K}_{\mathrm{I}}\right)$ and stress intensity factor for mode-II problem ( $\left.\mathrm{K}_{\mathrm{II}}\right)$. Rectangular finite plate with double crack (parallel and non-parallel) inclined at different angles with the loading axis has been used in the present investigation for determination of mixed mode (mode I, mode II) stress intensity factors under biaxial loading condition by using ANSYS Software. The accuracy of the present method is validated by comparing the results obtained by photo elastic method. 


\section{MATERIAL AND METHODS}

\section{Specimen geometry and assumptions}

T $\mathrm{n}$ the present investigation rectangular thin plate with centre inclined crack are used in FE modelling. The different crack configurations are shown in Figs. 1-2. The thickness of the plate is kept $1 \mathrm{~mm}$; length and width of the plates are kept $100 \mathrm{~mm}$ and $100 \mathrm{~mm}$ respectively. Two cracks at the centre of the plate are separated by an offset distance $\mathrm{H}$.

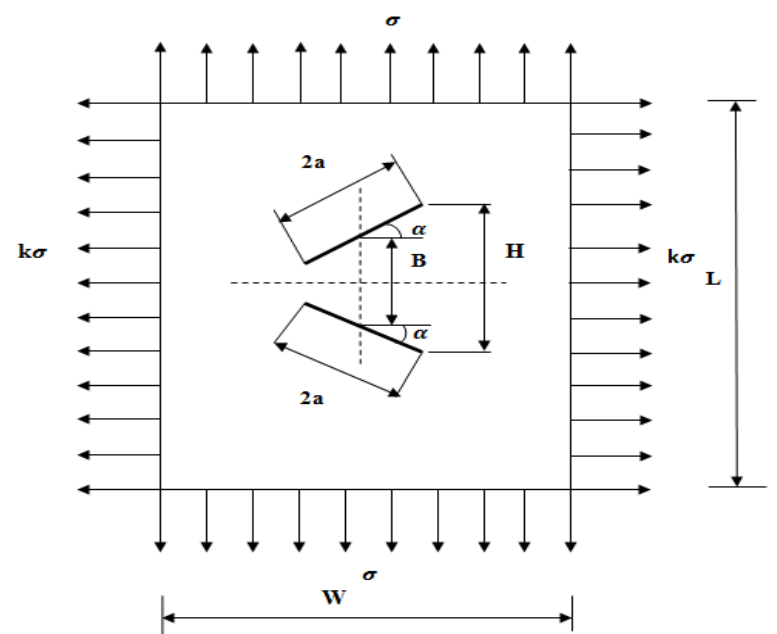

Figure 1: Specimen geometry of two non parallel central inclined cracks.

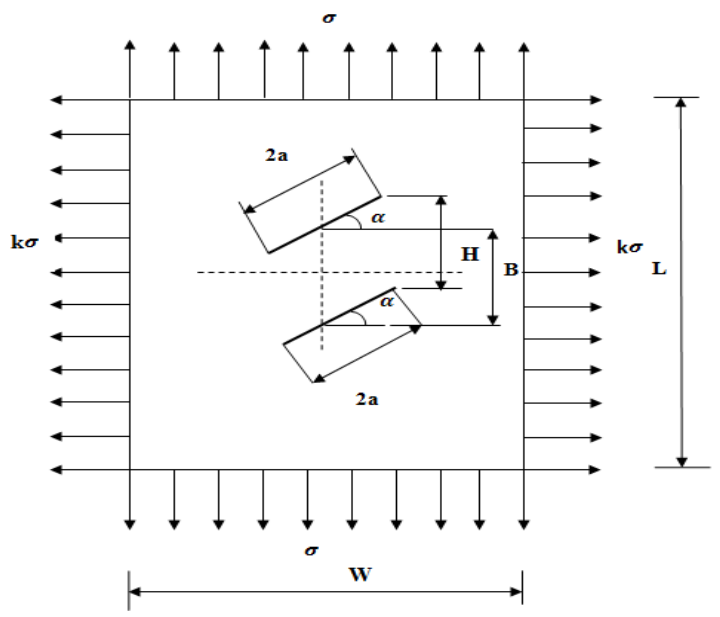

Figure 2: Specimen geometry of two parallel central inclined cracks.

\begin{tabular}{ccc}
\hline Specimen material & Young's modulus $(\mathrm{GPa})$ & Poisson's ratio \\
Steel & 210 & 0.3 \\
\hline
\end{tabular}

Table 1: Material properties.

\section{Method}

Stress intensity factors (mode-I and mode-II) have been calculated for a thin steel plate under plane strain condition containing central inclined multiple cracks for different conditions and orientations (as shown in Figs. 1-2) by ANSYS software. A single central crack model are also analysed by present method and results are verified by available experimental results of Singh and Gope [9] obtained by photo elastic method.

PLANE 82 (8-nod 2-D) elements shown in Fig 3 have been used in the analysis. PLANE 82 elements provide more accurate results for mixed (quadrilateral-triangular) automatic meshes and can tolerate irregular shapes without much loss of accuracy. The 8-node elements have compatible displacement shapes and are well suited to model curved boundaries. The element may be used as a plane element or as an axis symmetric element. The element has plasticity, creep, swelling, stress stiffening, large deflection, and large strain capabilities.
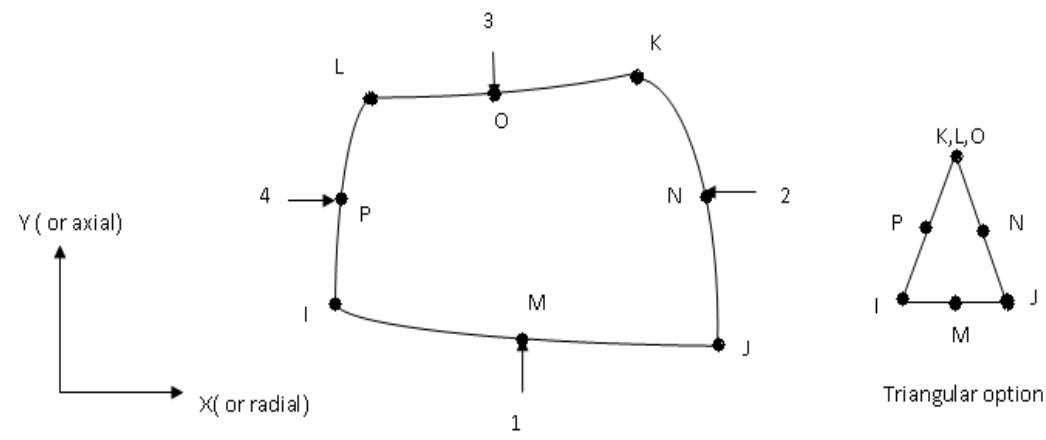

Triangular option

Figure 3: PLANE 82 elements with 8-nodes. 
All type of solution data of interest can be obtained in POST1 command like von Mises stress, principal stress, deformation, maximum stress, translations, failure criteria, SIFs, J integral. The data can be obtained for all the nodes and elements in tabular form or contour plots. In order to obtain the SIFs a path is defined manually by picking the five nodes at the crack face as shown in Fig. 4.

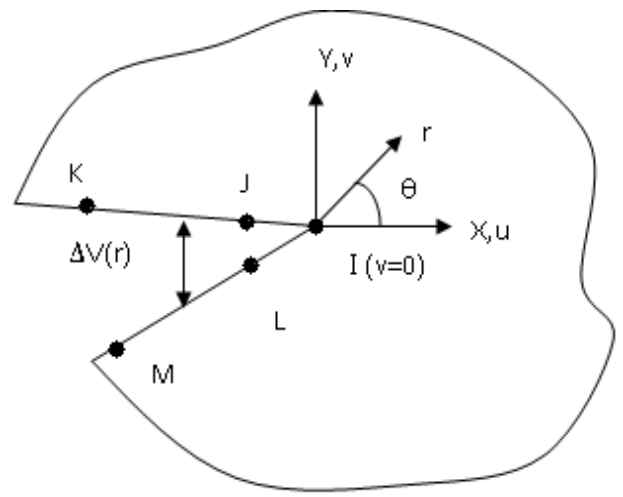

Figure 4: Representation of displacements to be used in analysis.

After defining the path the SIF's are obtained. The von Mises distribution around the crack tip can be obtained in the contour chart and can be used for further analysis. Image can be saved in the JPEG format. The postprocessor can give contour plot of the structure as shown below in Fig. 5. Von Mises stress distribution for a central inclined cracked in a plate is shown in Fig. 6.

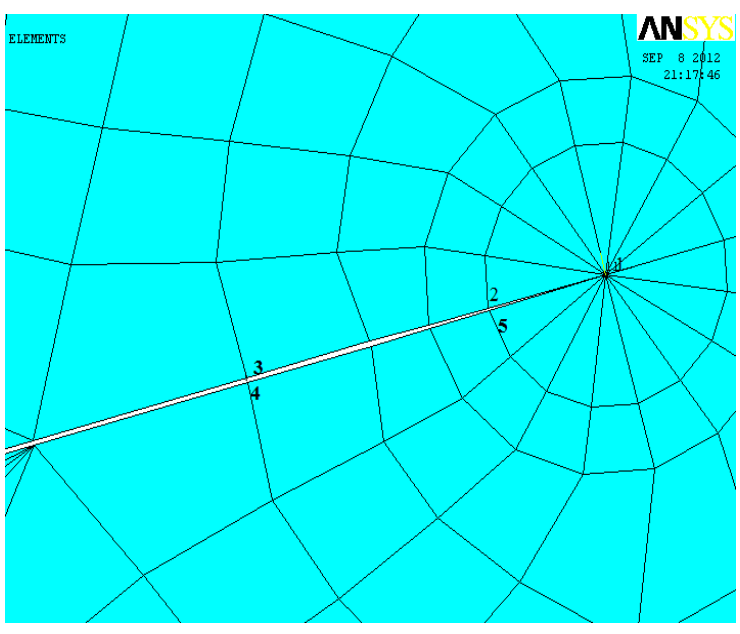

Figure 5: Defining the path node 1-2-3-4-5 for finding SIF.

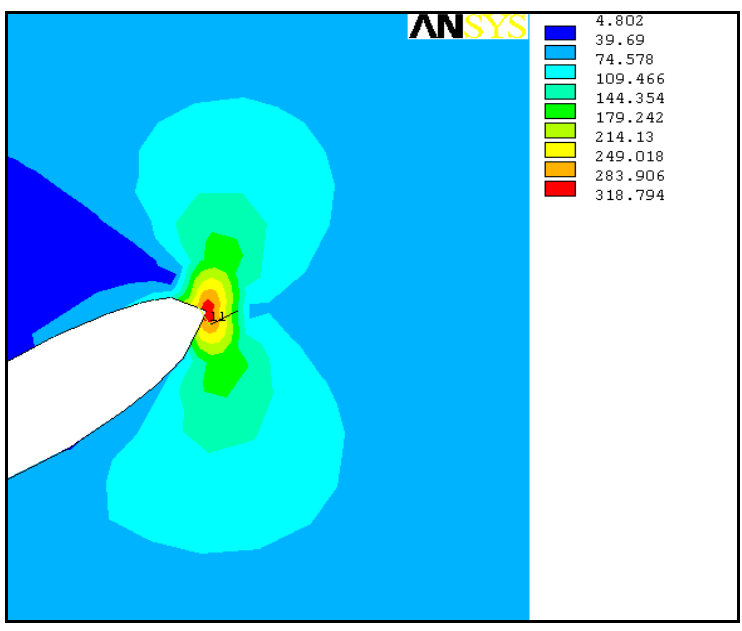

Figure 6: Von Mises stress distribution for inclined cracked in a plate.

\section{RESULTS AND DISCUSSION}

$\mathrm{V}$

alidation of the finite element approach with results available in literature or experimental results are most important for acceptance of the finite element method used in the computation. In the present investigation finite element method results are compared with the experimental results available in literature.

It is seen that $\mathrm{K}_{\mathrm{I}}$ and $\mathrm{K}_{\mathrm{II}}$ depends upon crack angle, biaxial load factor, constant stress term and geometry factor (a/W) and $(\mathrm{a} / \mathrm{L})$. The results are compared with the experimental results of Singh and Gope [9]. The effects of these parameters on stress intensity factors based on photoelastic analysis are modelled by Singh and Gope [9] as:

$$
K_{I}=\sigma \sqrt{\pi a}\{(1+k)-(1-k) \cos 2 \alpha\} f_{1}\left(\frac{L_{e}}{W_{e}}\right)
$$


where

$$
L_{e}=\frac{L}{2}-\alpha \cos \alpha
$$

and

$$
W_{e}=\frac{W}{2}-\alpha \sin \alpha
$$

where $f_{1}\left(\frac{L_{e}}{W_{e}}\right)$ is obtained from regression analysis of the experimental results as Singh and Gope [9],

$$
f_{1}\left(\frac{L_{e}}{W_{e}}\right)=a_{1}+a_{2}\left(\frac{L_{e}}{W_{e}}\right)+a_{3}\left(\frac{L_{e}}{W_{e}}\right)^{2}+a_{4}\left(\frac{L_{e}}{W_{e}}\right)^{3}+a_{5}\left(\frac{L_{e}}{W_{e}}\right)^{4}
$$

The coefficients (a1 to a5) are shown in Tab. 2 for various biaxial load factors. The effective length and width are defined in Fig. 7.

\begin{tabular}{cccccc}
\hline $\mathbf{K}$ & \multicolumn{5}{c}{ Coefficients } \\
1.0 & 2958.13 & -12319.36 & 19224.87 & -13324.242 & 3460.51 \\
1.2 & 4537.08 & 18372.43 & 27972.43 & -18972.07 & 4837.87 \\
1.4 & 15558.09 & -64654.20 & 100712.02 & -69686.75 & 18072.87 \\
1.6 & 25511.84 & -105574.57 & 163730.04 & -112775.23 & 29110.39 \\
1.8 & 13629.04 & -56212.08 & 87054.91 & -59991.82 & 15522.33 \\
2.0 & 42527.06 & -175971.91 & 272858.97 & -187899.41 & 48486.72 \\
\hline
\end{tabular}

Table 2: The coefficients of Eq. (2) [9].

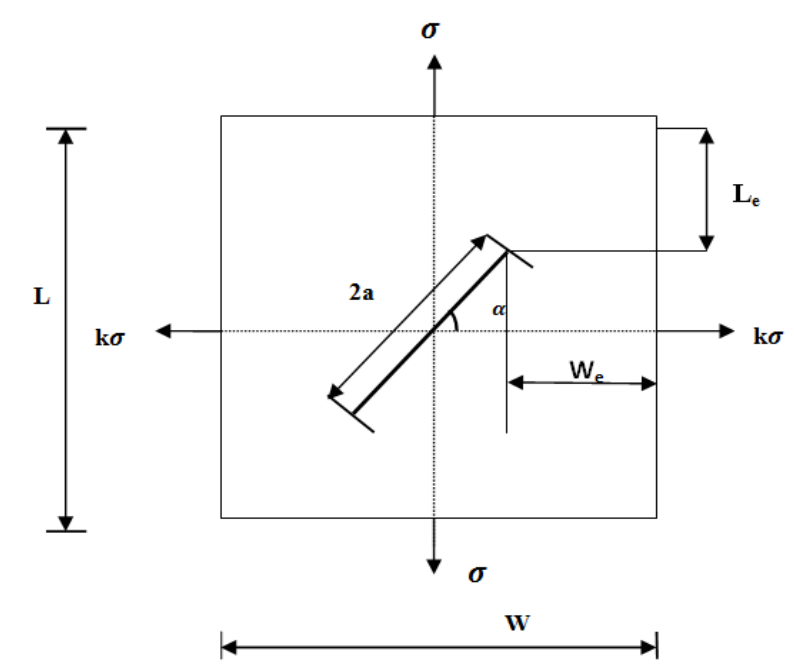

Figure 7: Effective length and effective width in the specimen.

The correlation coefficient in all cases are found to be greater than 0.90 .

The variation of $K_{I}$ with crack inclination angle $(\alpha)$ obtained by experimental method and FEM are shown in Fig. 8. It is observed that result of $K_{I}$ obtained from finite element approach using commercial software ANSYS are very close to experimental results of Singh and Gope [9]. It means finite element modelling using ANSYS software can be used to determine stress intensity factor $\mathrm{K}_{\mathrm{I}}$ for any complex crack configurations too. 


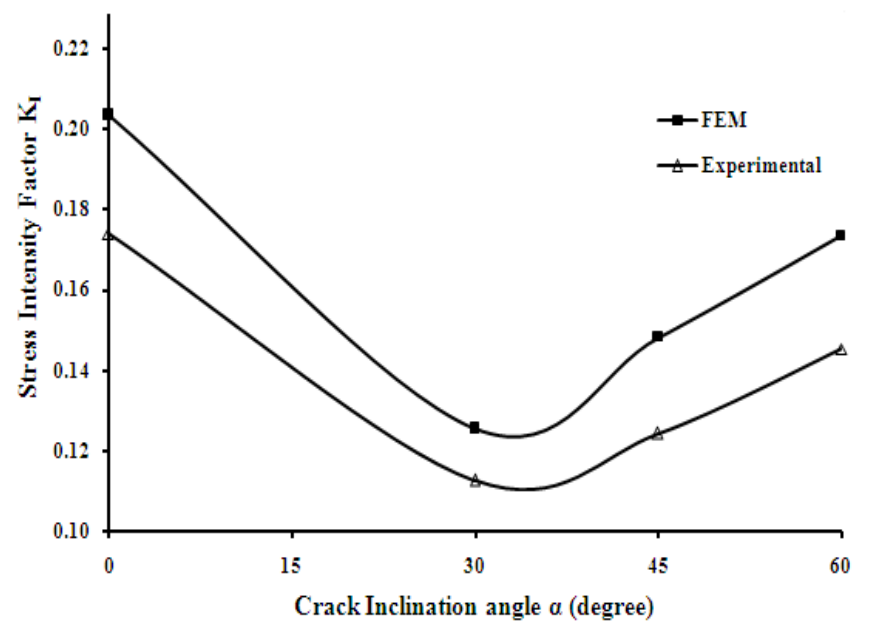

Figure 8: Comparison of stress intensity factor $\mathrm{K}_{\mathrm{I}}$ for load $\sigma=1.125 \mathrm{~N} / \mathrm{mm}^{2}$, biaxial load factor $=1$ and a $/ \mathrm{W}=0.06$.

\section{Effect of crack inclination angle on KI for two non-parallel cracks}

When there are two parallel and symmetric cracks in a plate then $\mathrm{K}_{\mathrm{I}}$ for lower $\mathrm{K}_{\mathrm{I}}(\mathrm{L})$ and upper $\mathrm{K}_{\mathrm{I}}(\mathrm{U})$ crack decreases with the increase of crack inclination angle as shown in Fig. 9.

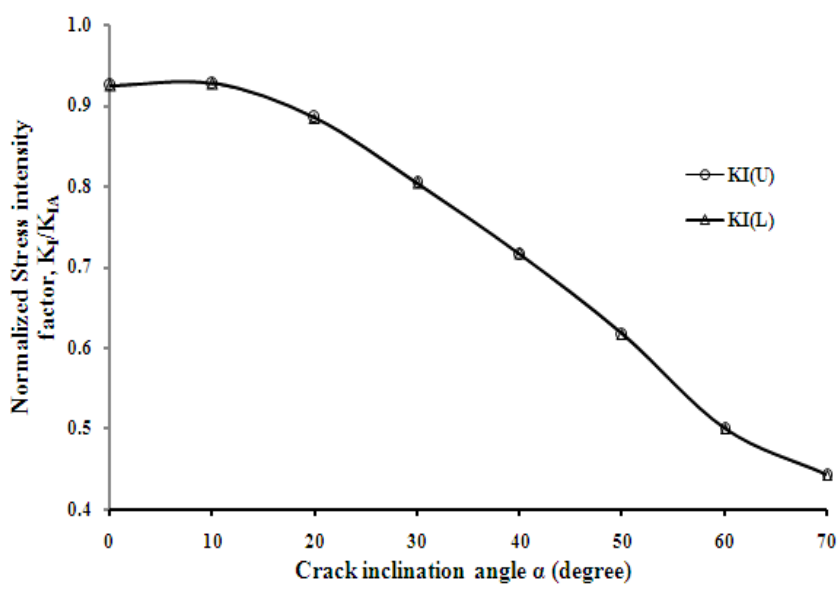

Figure 9: Effect of crack inclination angle $\alpha$ on $\mathrm{K}_{\mathrm{I}}$ for two non parallel crack; $\mathrm{a} / \mathrm{W}=0.08, \mathrm{k}=0.75, \mathrm{~S}=1.5$ and $\mathrm{B}=24$.

\section{Effect of crack inclination angle on $K_{I}$ for two parallel cracks}

When there are two parallel cracks in a plate then $\mathrm{K}_{\mathrm{I}}$ for lower and upper crack decrease with the increase in crack inclination angle, whereas upper crack has slightly more value than the lower crack as shown in Fig. 10. Fig. 10 shows that for lower and higher crack inclination angle, $\mathrm{K}_{\mathrm{I}}$ for lower and upper crack are approximately same because cracks are tends to parallel to either major or minor load axis, and are close mode I or mode II condition and hence there is negligible variation in the $\mathrm{K}_{\mathrm{I}}$ for lower and upper crack.

\section{Effect of crack inclination angle a on two non-parallel cracks}

When there is two parallel and symmetric crack in a plate $\mathrm{K}_{I I}$ for lower $\mathrm{K}_{\mathrm{II}}(\mathrm{L})$ and upper $\mathrm{K}_{\mathrm{II}}(\mathrm{U})$ crack the value of $\mathrm{K}_{\mathrm{II}}$ are approximately same for both the crack as shown in Fig. 11 and it increases up to $\alpha=450$ and then it starts decreasing hence, maximum value is observed at $\alpha=450$.

\section{Effect of crack inclination angle a on two parallel cracks}

When there are two parallel cracks in a plate then $K_{I I}$ increases with the increase of crack inclination angle for upper and lower crack up to 450 and then it starts decreasing as shown in Fig. 12. Hence, maximum value is obtained at $\alpha=450$. 


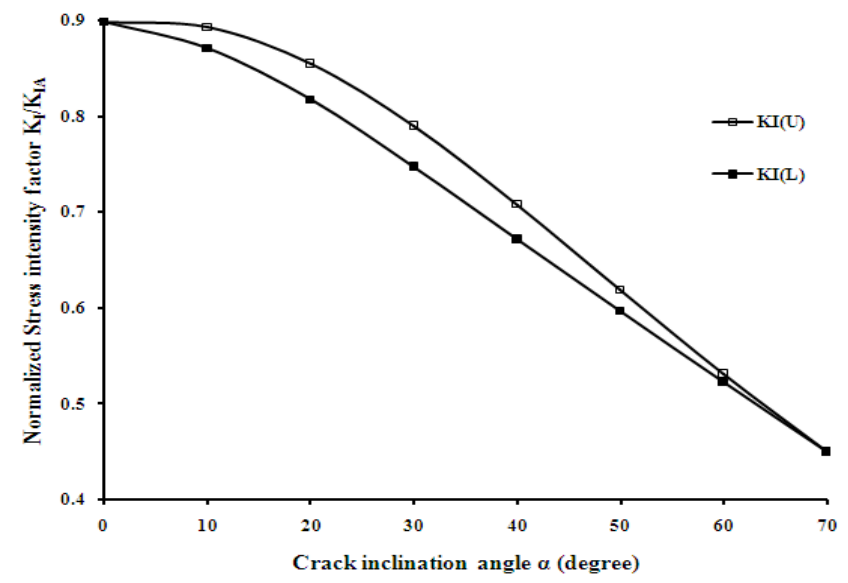

Figure 10: Effect of crack inclination angle $\alpha$ on $\mathrm{K}_{\mathrm{I}}$ for two parallel crack; $\mathrm{a} / \mathrm{W}=0.08, \mathrm{k}=0.75, \mathrm{~S}=1.5$ and $\mathrm{B}=24$.

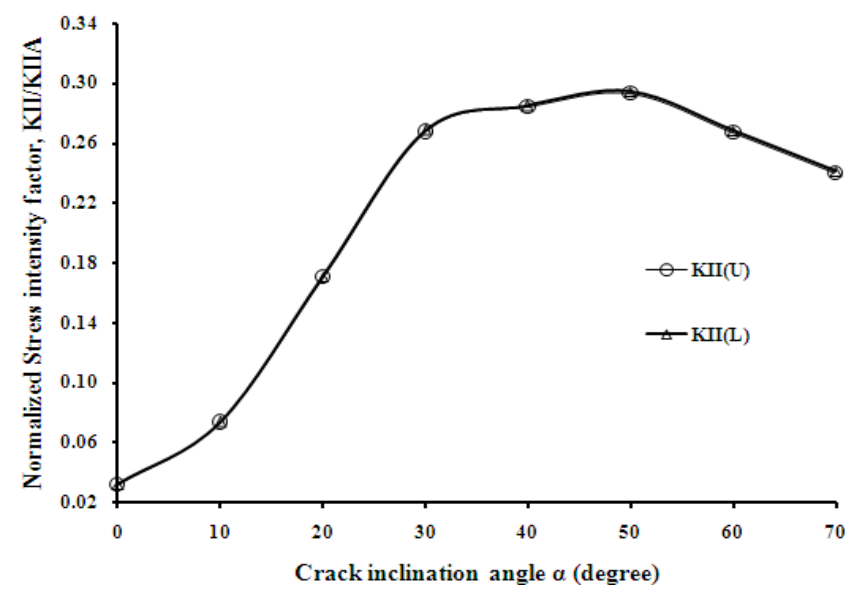

Figure 11: Effect of crack inclination angle $\alpha$ on $\mathrm{K}_{\mathrm{I}}$ for two non-parallel cracks; $\mathrm{a} / \mathrm{W}=0.08, \mathrm{k}=0.75, \mathrm{~S}=1.5$ and $\mathrm{B}=24 \mathrm{~mm}$.

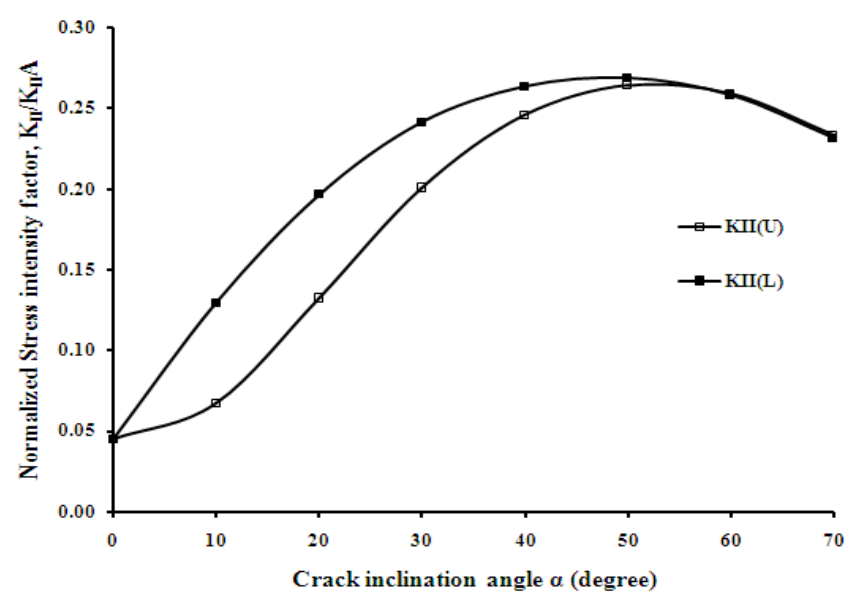

Figure 12: Effect of crack inclination angle $\alpha$ on $K_{I}$ for two parallel cracks; $a / W=0.08, k=0.75, S=1.5$ and $B=24 \mathrm{~mm}$.

\section{CONCLUSIONS}

ffects of crack inclination angle on stress intensity factors for two parallel and non parallel cracks are analysed and found to have significant effect on lower and upper crack. The stress intensity factors for non parallel cracks have similar value for upper and lower cracks, whereas in case of parallel cracks the value of stress intensity factor is 
lower for lower crack in comparison to upper crack.

\section{REFERENCES}

[1] C.E. Inglis, Transactions-Institute of Naval Architect, 55 (1913) 219.

[2] A.A. Griffith, Trans. Royal Soci. London, 221 (1920) 163.

[3] H. M. Westgaard, J. Appl. Maths Mech., 6 (1939) A49.

[4] G. R. Irwin, Trans. ASME, J. Appl. Mech., 24(3) (1957) 361.

[5] T. Wen-Ye, U. Gabbert, European J. Mech. A/Solids, 23 (2004) 599.

[6] Y. Xiangqiao, M. Changing, Interaction of Multiple Cracks in a Rectangular Plate, Appl. Math. Modelling. (2012) Article in press.

[7] K. van der Walde, Int. J. Fatigue. 27 (2005) 1509.

[8] W. Wang, X. Zeng, J. Ding, Engineering and Technology, 70 (2010) 587.

[9] V.K. Singh, P.C. Gope, Journal of Solid Mechanics, 3 (2009) 233. 